\title{
Influência da profundidade de semeadura na formação de mudas de pepino (Cucumis sativus L.)
}

\author{
Naiane Caetano da Silva Leal \\ Discente de Agronomia na Universidade Federal Rural da Amazônia e bolsista do \\ Programa Institucional de Bolsas de Iniciação Científica- PIBIC, Campus de Parauapebas-PA \\ 凶naianecaet.18@gmail.com \\ Ruanis Silva Araújo \\ Discente de Agronomia na Universidade Federal Rural da Amazônia e bolsista do \\ Programa Institucional de Voluntário de Iniciação Científica- PIVIC, Campus de Parauapebas-PA \\ Diogo Leandro Silva Carvalho \\ Discente de Agronomia na Universidade Federal Rural da Amazônia \\ e bolsista do Programa de Monitoria, Campus de Parauapebas-PA \\ Gabrielly Pereira de Araújo \\ Discente de Agronomia na Universidade Federal Rural da Amazônia e bolsista do \\ Programa Institucional de Voluntário de Iniciação Científica- PIVIC, Campus de Parauapebas-PA \\ Kelly de Nazaré Maia Nunes \\ Doutorado em Agronomia, pela Universidade Estadual Paulista "Júlio de Mesquita Filho" - UNESP/ Botucatu \\ Professora Adjunta na Universidade Federal Rural da Amazônia Campus de Parauapebas-PA \\ Josiane Pereira da Silva \\ Doutorado em Agronomia, pela Universidade Estadual Paulista “Júlio de Mesquita Filho" - UNESP/Jaboticabal \\ Professora Adjunta na Universidade Federal Rural da Amazônia Campus de Parauapebas-PA
}

Recebido em 10 de agosto de 2019

Aceito em 3 de setembro de 2019

\section{Resumo:}

A profundidade de deposição da semente é um fator de grande importância na semeadura, e afeta diretamente na qualidade da germinação, entretanto ainda há poucos trabalhos científicos que abordem a temática da profundidade de semeadura das hortaliças, principalmente no tocante à cultura do pepino. Assim o presente trabalho teve como objetivo avaliar a influência da profundidade de semeadura na formação de mudas de pepino. Foram utilizadas sementes de pepino (Cucumis sativus L.) cv. Aodai semeadas em bandejas de polietileno de 128 células com substrato comercial a $0 \mathrm{~cm}, 0,5 \mathrm{~cm}, 1,0 \mathrm{~cm}$ e $1,5 \mathrm{~cm}$ de profundidade, durante o experimento foram avaliados o tempo e porcentagem de germinação, a altura das plântulas e diâmetro do caule aos 7, 14 e 21 DAS. Para a análise dos dados utilizou-se o programa estatístico Sisvar, com Analise de Variância e comparação de médias pelo teste de Tukey, a $5 \%$ de probabilidade. A semeadura a $0 \mathrm{~cm}$ de profundidade não foi satisfatória em nenhum dos quesitos avaliados, entretanto a semeadura a $1,0 \mathrm{~cm}$ de profundidade se destacou das demais nas avaliações de altura de plântula e diâmetro de caule, sendo, portanto, a mais indicada para a produção de mudas de pepino em bandejas de 128 células.

Palavras-Chave: Germinação, semeadura, plântula, bandeja de polietileno, diâmetro. 


\title{
Influence of sowing depth on the formation of cucumber (Cucumis sativus L.)
}

\begin{abstract}
:
Depth of seed deposition is a major factor in sowing, and directly affects the quality of germination, however there are still few scientific studies addressing the topic of depth of sowing of vegetables, especially regarding cucumber. Thus, the present work aimed to evaluate the influence of sowing depth on cucumber seedling formation. Cucumber seeds (Cucumis sativus L.) cv. Then sown in 128-cell polyethylene trays with commercial substrate at $0 \mathrm{~cm}, 0.5 \mathrm{~cm}, 1.0 \mathrm{~cm}$ and $1.5 \mathrm{~cm}$ depth, during the experiment, germination time and percentage, seedling height and stem diameter at 7, 14 and 21 DAS. For data analysis we used the statistical program Sisvar, with analysis of variance and comparison of means by Tukey test, at $5 \%$ probability. Sowing at $0 \mathrm{~cm}$ depth was not satisfactory in any of the evaluated items, however sowing at $1.0 \mathrm{~cm}$ depth stood out from the others in the seedling height and stem diameter evaluations, being therefore the most suitable for cucumber seedling production in 128-cell trays.
\end{abstract}

Keywords: Germination, seeding, seedling, polyethylene tray, diameter.

\section{Influencia de la profundidad de semilla en la formación de pepino (Cucumis sativus L.)}

\section{Resumen:}

La profundidad de la deposición de semillas es un factor importante en la siembra, y afecta directamente la calidad de la germinación, sin embargo, todavía hay pocos estudios científicos que aborden el tema de la profundidad de la siembra de hortalizas, especialmente en relación con el pepino. Por lo tanto, el presente trabajo tuvo como objetivo evaluar la influencia de la profundidad de siembra en la formación de plántulas de pepino. Semillas de pepino (Cucumis sativus L.) cv. Luego sembró en bandejas de polietileno de 128 celdas con sustrato comercial a $0 \mathrm{~cm}, 0,5 \mathrm{~cm}, 1,0 \mathrm{~cm}$ y $1,5 \mathrm{~cm}$ de profundidad, durante el experimento, el tiempo de germinación y el porcentaje, la altura de las plántulas y el diámetro del tallo a los 7, 14 y 21 DAS. Para el análisis de datos utilizamos el programa estadístico Sisvar, con análisis de varianza y comparación de medias mediante la prueba de Tukey, con una probabilidad del 5\%. La siembra a $0 \mathrm{~cm}$ de profundidad no fue satisfactoria en ninguno de los artículos evaluados, sin embargo, la siembra a 1,0 cm de profundidad se destacó de las demás en las evaluaciones de altura de la plántula y diámetro del tallo, siendo por lo tanto la más adecuada para la producción de plántulas de pepino en bandejas de 128 celdas.

Palabras Clave: Germinación, siembra, plántulas, bandeja de polietileno, diámetro.

\section{INTRODUÇÃO}

O pepineiro, Cucumis sativus L. (Cucurbitaceae), é uma hortaliça fruto de crescimento indeterminado e anual, de grande aceitação em todas as regiões brasileiras, e é consumido 
das mais variadas formas, sendo elas em sanduíches, conserva, curtido em salmoura na forma de picles, in natura em saladas e sopas, também é utilizado como matéria prima na fabricação de cosméticos e medicamentos devido a presença de propriedades nutracêuticas (MICHEREFF FILHO et al., 2012).

No mercado brasileiro há quatro tipos de pepinos: "caipira", "conserva", "japonês" e “aodai”. O pepino Cucumis sativus cv. Aodai é caracterizado por apresentar frutos de coloração verde-escura e formato cilíndrico, os frutos possuem sabor agradável e muito apreciado nas regiões metropolitanas de São Paulo onde apresenta um grande volume de vendas, consistindo no principal grupo do ponto de vista comercial (CARVALHO et al., 2013).

Um fator de grande importância na semeadura é a profundidade de deposição das sementes, que afeta diretamente na germinação, sendo influenciada pela temperatura, teor de água, tipo de solo, além de outros fatores. A semente deve ser colocada a uma profundidade ideal, que mesma tenha contato com o solo úmido, tendo como consequência uma boa germinação (SILVA et al., 2008).

Atualmente há poucos trabalhos científicos que abordem a temática da profundidade de semeadura das hortaliças, sendo esse acervo ainda mais escasso quando se trata da cultura do pepino. Portanto o presente trabalho possuiu o objetivo de avaliar a influência da profundidade de semeadura na formação de mudas de pepino.

\section{MATERIAL E MÉTODOS}

O experimento foi conduzido em Parauapebas-PA ( $6^{\circ}$ 3’ 43,41” S, 49ํ51' 23,38” W), em maio de 2019. A temperatura média no período do experimento foi de $30^{\circ} \mathrm{C}$ e UR de $86,5 \%$. A semeadura foi realizada em bandejas de polietileno de 128 células, com semeio de 1 semente por célula. A semeadura foi realiza em 4 profundidades diferentes: $\operatorname{com~} 0 \mathrm{~cm}, 0,5 \mathrm{~cm}, 1,0 \mathrm{~cm} \mathrm{e}$ $1,5 \mathrm{~cm}$ de profundidade, configurando os 4 tratamentos deste trabalho. As bandejas semeadas foram acondicionadas em bancada sem cobertura contra o sol, e irrigadas manualmente, com uso de borrifador, na frequência de duas vezes ao dia, nas horas mais frescas.

As células das bandejas foram preenchidas com substrato comercial, e as sementes de pepino (Cucumis sativus L.) cv. Aodai foram despostas no centro das células e penetradas no 
substrato com auxílio de um instrumento cilíndrico de $8 \mathrm{~cm}$ de altura e $0,8 \mathrm{~cm}$ de diâmetro, graduado de 0 a $1,5 \mathrm{~cm}$, ao qual fora empregado para afundar a semente conforme profundidade pretendida, exceto o tratamento a $0 \mathrm{~cm}$ de profundidade. Em seguida o espaço resultante da perfuração do substrato com a semente foi preenchido com mais substrato.

O tempo de germinação foi avaliado tendo como referência o dia do semeio (dia 0). A altura da plântulas e diâmetro do caule foram avaliados aos 7, 14 e 21 dias após a semeadura (DAS). A altura das plântulas foi obtida com auxílio de régua, medindo-se o comprimento desde o colo até o ápice das plântulas. 0 diâmetro do caule foi obtido com auxílio de paquímetro analógico medindo na base das plântulas, logo acima do substrato.

O delineamento experimental foi em blocos ao acaso, com 4 repetições cada, e 21 plantas por tratamento em sistema de duplicata. Para a análise dos dados utilizou-se o programa estatístico Sisvar, realizando-se a Análise de Variância com comparação de médias pelo teste de Tukey, a 5\% de probabilidade.

\section{RESULTADOS E DISCUSSÃO}

A profundidade de semeadura interferiu na porcentagem de emergência das plântulas de pepino, sendo a profundidade de $0 \mathrm{~cm}$, a que demonstrou menor eficiência de emergência e maior tempo para começar a imergir ( $34,8 \%$ e 5 dias, respectivamente) (Tabela 1). Isso pode ser explicado pela exposição excessiva ao sol, que comprometera a capacidade de termo regulação da semente, bem como a umidade requerida pela mesma para iniciar o processo de germinação. Jeller e Perez (1997) afirmam que semeaduras muito rasas favorecem danos decorrentes da irrigação, bem como a exposição e destruição da raiz principal.

Nos demais tratamentos não houve diferença estatística, indicando que a 0,5, 1,0 e 1,5 $\mathrm{cm}$ de profundidade a semente possui condições de umidade e temperatura semelhantes para a germinação. 
Tabela 1. Porcentagem de emergência - EMG (\%) e tempo de emergência - EMG (dias)

\begin{tabular}{ccc}
\hline PROFUNDIDADES & EMG (\%) & EMG (dias) \\
\hline $0 \mathrm{~cm}$ & 34,8 & 5 \\
$0,5 \mathrm{~cm}$ & 99,6 & 2 \\
$1,0 \mathrm{~cm}$ & 99,8 & 2 \\
$1,5 \mathrm{~cm}$ & 99,6 & 3 \\
\hline
\end{tabular}

Fonte: Própria.

A profundidade de semeadura influenciou na altura das plântulas e no diâmetro do caule (Tabela 2). Aos 7, 14 e 21 DAS verificou-se que a profundidade $0 \mathrm{~cm}$, prejudicou o desenvolvimento normal da muda, apresentando valores inferiores quando comparados as demais profundidades avaliadas. Isso se deve ao deficiente e superficial desenvolvimento do sistema radicular, nitidamente visível no substrato, além do comportamento prostrado das mudas, que indica falta de apoio e firmeza da raiz.

De acordo com Ghorbani et al. (1999) e Dias Filho (1996) sementes posicionadas na superfície do solo apresentam menor emergência de plântulas quando comparadas aquelas dispostas à pequenas profundidades.

Em estudo realizado por Medina e Couto (1971) verificou o tombamento de plântulas de quiabo quando semeado superficialmente no substrato, tombamento na ordem de $7 \%$ em função do desequilíbrio de massa entre o sistema radicular e a parte aérea (apud TILLMANN et al., 1994, p. 262). No caso do presente trabalho esse comportamento foi verificado com semeadura à $0 \mathrm{~cm}$ de profundidade.

Tabela 2. Altura de plântulas (AP) e Diâmetro do caule (DC) aos 7, 14 e 21 dias após a semeadura (DAS).

\begin{tabular}{ccccccc}
\hline \multirow{2}{*}{ PROFUNDIDADE } & \multicolumn{2}{c}{ 7 DAS } & \multicolumn{2}{c}{ 14 DAS } & \multicolumn{2}{c}{ 21 DAS } \\
\cline { 2 - 7 } & AP $(\mathbf{c m})$ & DC $(\mathbf{m m})$ & AP $(\mathbf{c m})$ & DC $(\mathbf{m m})$ & AP $(\mathbf{c m})$ & DC $(\mathbf{m m})$ \\
\hline $0 \mathrm{~cm}$ & $4,58 \mathrm{~d}$ & $0,92 \mathrm{~d}$ & $6,11 \mathrm{~d}$ & $1,33 \mathrm{~d}$ & $7,12 \mathrm{~d}$ & $1,89 \mathrm{~d}$ \\
$0,5 \mathrm{~cm}$ & $6,83 \mathrm{c}$ & $1,53 \mathrm{bc}$ & $7,43 \mathrm{c}$ & $2,61 \mathrm{bc}$ & $9,88 \mathrm{bc}$ & $3,49 \mathrm{bc}$ \\
$1,0 \mathrm{~cm}$ & $8,62 \mathrm{a}$ & $1,84 \mathrm{a}$ & $9,41 \mathrm{a}$ & $3,12 \mathrm{a}$ & $12,53 \mathrm{a}$ & $3,66 \mathrm{a}$ \\
$1,5 \mathrm{~cm}$ & $7,81 \mathrm{~b}$ & $1,56 \mathrm{~b}$ & $8,54 \mathrm{~b}$ & $2,71 \mathrm{~b}$ & $10,14 \mathrm{~b}$ & $3,53 \mathrm{ab}$ \\
\hline C.V. & 6,20 & 11,07 & 5,03 & 10,30 & 9,40 & 11,20 \\
\hline
\end{tabular}

Nota: Médias seguidas de mesma letra não diferem estatisticamente entre si, maiúscula na coluna e minúscula na linha, pelo teste de Tukey a $5 \%$ de probabilidade.

Fonte: Própria. 
A profundidade de $1,0 \mathrm{~cm}$ mostrou-se superior quanto aos quesitos avaliados, com valores crescentes dos 7 aos 21 DAS. Em estudo realizado por Vieira et al. (2018) mudas de pepino semeadas a 1,0 $\mathrm{cm}$ de profundidade aos 30 DAS possuíam altura das mudas e diâmetro do caule de 3,73 $\mathrm{cm}$ e 2,86 $\mathrm{mm}$ respectivamente, dado esse que diverge do presente trabalho, neste aos 21 DAS, que foi o período máximo do experimento a altura das plântulas e diâmetro do caule foi de $12,53 \mathrm{~cm}$ e 3,66 $\mathrm{mm}$ respectivamente.

As profundidades de 0,5 e 1,5 cm apresentaram valores muito parecidos ao longo dos 7, 14 e 21 DAS, inclusive a primeira não diferiu estatisticamente da segunda em todas as avaliações de diâmetro do caule. Já no quesito altura das plântulas verificou-se que a profundidade de $1,5 \mathrm{~cm}$ de semeadura manteve valores superiores à de $0,5 \mathrm{~cm}$ de profundidade, em uma constante crescente até as 21 DAS, momento em que a profundidade de 0,5 cm não diferiu estatisticamente de $1,5 \mathrm{~cm}(3,49 \mathrm{~mm})$.

\section{CONCLUSÕES}

Sob as condições do presente trabalho, a semeadura a $0 \mathrm{~cm}$ foi inferior em todos os quesitos, incluindo porcentagem de germinação e tempo de emergência, não sendo indicada para a cultura do pepino.

A profundidade de semeadura de 0,5 a 1,5 $\mathrm{cm}$ demonstrou maiores porcentagens de germinação, e menor tempo de emergência.

A semeadura de 1,0 cm foi superior nas avaliações de altura de plântula e diâmetro de caule, sendo esta a mais indicada para a produção de mudas de pepino. 


\section{REFERÊNCIAS BIBLIOGRÁFICAS}

CARVAlHO, A. D. F.; AMARO, G. B.; LOPES J.F.; VILELA, N.J.; MICHEREFF FILHO, M.; ANDRADE R. A cultura do pepino. Brasília: Distrito Federal (Circular técnica), 2013. Disponível em: <http://ainfo.cnptia.embrapa.br/digital/bitstream/item/81827/1/ct-113.pdf>. Acesso em: 29 mai. 2019.

DIAS FILHO, M. B. Germination and emergence of Stachytarpheta cayennensis and Ipomoea asarifolia. Planta Daninha, v. 14, n. 2, p. 118-126, 1996. Disponível em: <http://dx.doi.org/10.1590/S0100-83581996000200005>. Acesso em: 03 jun. 2019.

GHORBANI, R.; SEEL, W.; LEIFERT, C. Effects of environmental factors on germination and emergence of Amaranthus retroflexus. Weed Sci., v. 47, n. 5, p. 505-510, 1999. Disponível em: <https://doi.org/10.1017/S0043174500092183>. Acesso em: 05 jun. 2019.

JELLER, H.; PEREZ, S. C. J. G. A. Efeito da salinidade e semeadura em diferentes profundidades na viabilidade e no vigor de Copaifera langsdorffii Desf. - Caesalpiniaceae. Revista Brasileira de Sementes, Pelotas, v. 19, n. 2, p. 218224. 1997. Disponível em: <http://dx.doi.org/10.17801/0101-3122/rbs.v19n2p218-224>. Acesso em: 30 mai. 2019.

MICHEREFF FILHO, M.; MOURA, A. P.; GUIMARÃES J. A.; REYES C. P.; CARVALHO A. D. F.; AMARO G, B.; LOPES J. F.; LIZ R. S. Recomendações técnicas para o controle de pragas do pepino. Embrapa Hortaliças-Circular Técnica
(INFOTECA-E),
2012.
Disponível
em:

<https://www.infoteca.cnptia.embrapa.br/bitstream/doc/941571/1/ct1091.pdf>. Acesso em: 03 jun. 2019.

SILVA, R. P.; CORÁ, J. E.; FURLANI, C. E. A.; LOPES, A. Efeito da profundidade de semeadura e de rodas compactadoras submetidas a cargas verticais na temperatura e no teor de água do solo durante a germinação de sementes de milho. Ciência e Agrotecnologia, Lavras, v.32, n.3, p.929-937, 2008. Disponível em: <https://repositorio.unesp.br/handle/11449/30175>. Acesso em: 02 jun. 2019.

TILLMANN, M. A. A.; PIANA, Z.; CAVARIANI, C.; MINAMI, K. Efeito da profundidade de semeadura na emergência de plântulas de tomate (Lycopersicon esculentum Mill.). Scientia Agricola, v. 51, n. 2, p. 260-263, 1994. Disponível em: <http://dx.doi.org/10.1590/S0103-90161994000200010>. Acesso em: 01 jun. 2019.

VIEIRA, M. T.; SALLES, J. S. S.; SOUZA, L. G. P.; ALVES, V. C. D.; FERREIRA, L. M. Formação de Mudas de Pepineiro em Diferentes Profundidades de Semeadura. Cadernos de Agroecologia, v. 13, n. 2, p. 8-8, 2018. Disponível em: <http://cadernos.aba-agroecologia.org.br/index.php/cadernos/article/view/2144>. Acesso em: 04 jun. 2019.

\section{(c) $)$ EY}

Este trabalho está licenciado com uma Licença Creative Commons - Atribuição 4.0 Internacional. 